\title{
QUALIDADE MICROBIOLÓGICA, ACEITABILIDADE E VALOR NUTRICIONAL DE BARRAS DE CEREAIS FORMULADAS COM POLPA E AMÊNDOA DE BARU
}

\author{
JEAN CARLOS RODRIGUES LIMA* \\ JULLYANA BORGES DE FREITAS** \\ LUDMILA DE PAULA CZEDER ${ }^{\star \star *}$ \\ DANIELA CANUTO FERNANDES* \\ MARIA MARGARETH VELOSO NAVES S*** $^{*}$
}

\begin{abstract}
Este trabalho teve como objetivo avaliar a qualidade microbiológica, a aceitabilidade e as características nutricionais de barras de cereais formuladas com polpa e amêndoa de baru (fruto nativo do Cerrado). Os frutos foram colhidos nas regiões Leste e Sudeste do estado de Goiás, em agosto de 2008. Foram preparadas formulações de barras de cereais com proporção fixa de amêndoa em substituição às castanhas e às frutas secas e proporções crescentes de polpa de baru (0\%, 5\% e 10\%) em substituição ao farelo de aveia. As barras de cereais foram avaliadas quanto à qualidade microbiológica por meio da contagem de coliformes, Bacillus cereus, Estafilococos coagulase positiva e pesquisa de Salmonella, e quanto à aceitação global, aparência e intenção de compra. As barras aceitas foram submetidas à análise da composição centesimal, incluindo fibra alimentar total e suas frações solúvel e insolúvel. Todas as amostras estavam de acordo com os padrões microbiológicos para alimentos. As barras de cereais alcançaram boa aceitação global e bons níveis de intenção de compra. As barras de cereais apresentaram teores de carboidratos e lipídios semelhantes às barras comerciais e conteúdo elevado de proteína (10,64g/100 g) em decorrência da adição da amêndoa de baru, fonte de proteína e de lipídios de boa qualidade nutricional. Barras de cereais formuladas com a polpa e amêndoa de baru são fontes de energia, proteínas e carboidratos e apresentam alto teor de fibra alimentar $(15,72 \mathrm{~g} / 100 \mathrm{~g})$. A utilização integral do baru em alimentos processados agrega valor ao fruto e qualidade nutricional ao produto, contribuindo para o uso sustentável desse fruto nativo.
\end{abstract}

PALAVRAS-CHAVE: Dipteryx alata Vog.; BARRA DE CEREAIS; VALOR NUTRICIONAL; ACEITABILIDADE.

* Mestrandos em Ciência e Tecnologia de Alimentos, Programa de Pós-Graduação em Ciência e Tecnologia de Alimentos, Faculdade de Agronomia e Engenharia de Alimentos, Universidade Federal de Goiás (UFG), Goiânia, GO, Brasil (e-mail: jcarlosnut@yahoo.com.br; daninutufg@gmail.com).

** Mestre em Ciência e Tecnologia de Alimentos, docente, Instituto Federal de Educação, Ciência e Tecnologia de Goiás (IFG), Goiânia, GO, Brasil (e-mail: jullyananut@yahoo.com.br).

*** Mestre em Ciência e Tecnologia de Alimentos, nutricionista, Serviço de Assistência Especializada, Secretaria Municipal de Saúde, Rio Verde, GO, Brasil (e-mail: luczeder@hotmail.com).

*** Doutora em Ciência dos Alimentos, docente, UFG, Faculdade de Nutrição, Goiânia, GO, Brasil (e-mail: mnaves@fanut.ufg.br). 


\section{INTRODUÇÃO}

O Cerrado está localizado predominantemente no Planalto Central do Brasil, ocupando cerca de 20\% do território nacional (GOMES, MARTINS e TAMASHIRO, 2004). No final do século XX consolidou-se como região com potencial de desenvolvimento agropastoril. Em decorrência da ocupação desordenada ocorreram profundas alterações ambientais, com a descaracterização e destruição da vegetação nativa. Desta forma, muitas espécies frutíferas do Cerrado estão desaparecendo antes mesmo da realização de pesquisas relevantes sobre o potencial nutritivo e tecnológico de seus frutos (CORRÊA, 1999).

Dentre as frutíferas nativas do Cerrado, o baru (Dipteryx alata Vog.) apresenta potencial econômico e grande aceitação por seu sabor agradável ao paladar (SANO, RIBEIRO e BRITO, 2004). O barueiro, leguminosa arbórea de grande porte (15 a 25 metros de altura), frutifica entre os meses de agosto e outubro (LORENZI, 2002).

A polpa do baru apresenta elevado teor de carboidratos totais (aproximadamente 60\%) e alta concentração de fibras insolúveis (cerca de 30\%) (TOGASHI e SGARBIERI, 1994). Sua semente (amêndoa) apresenta elevados teores de proteínas (entre 23\% e 30\%) e de lipídios (cerca de 40\%), assemelhando-se à composição característica de nozes (FREITAS e NAVES, 2010; VENKATACHALAM e SATHE, 2006). Por essa semelhança, a amêndoa de baru tem sido reconhecida e usada em diferentes formulações em substituição às castanhas tradicionais, até mesmo na culinária internacional (CASTRO, 2009). A amêndoa de baru também pode ser considerada fonte de minerais, com destaque para cálcio, ferro e zinco (FERNANDES et al., 2010; FREITAS e NAVES, 2010; TAKEMOTO et al., 2001; TOGASHI e SGARBIERI, 1994; VALLILO, TAVARES e AUED, 1990).

Estudos sobre o aproveitamento alimentar dos recursos frutíferos do Cerrado têm demonstrado que algumas espécies nativas podem apresentar elevado potencial de aproveitamento tecnológico e econômico, como o caju-do-cerrado e o pequi (MARTINS, CUNHA e SILVA, 2008; RABÊLO et al., 2008; SOARES JÚNIOR et al., 2009). Uma alternativa alimentícia para o aproveitamento de frutos regionais são as barras de cereais, que constituem exemplos de produtos industrializados bem aceitos pela população por sua praticidade e conteúdo nutricional. Esses alimentos são formulados a partir de ingredientes sólidos (mistura de grãos, frutas secas, castanhas), ligantes (xarope de milho ou mel, açúcar, lecitina) e aromatizantes (GUIMARÃES e SILVA, 2009). O emprego da polpa e da amêndoa de baru em produtos industrializados pode enriquecê-los em termos nutricionais e agregar valor ao fruto, além de contribuir para a preservação da espécie nativa e o desenvolvimento regional sustentável.

O objetivo deste trabalho foi avaliar a qualidade microbiológica, a aceitabilidade e o valor nutricional de barras de cereais formuladas com polpa e amêndoa de baru.

\section{MATERIAL E MÉTODOS}

\subsection{OBTENÇÃO DOS FRUTOS}

Os frutos do barueiro foram colhidos no mês de agosto de 2008, nas regiões Leste e Sudeste do estado de Goiás. Na região Leste, os frutos foram coletados no município de Pirenópolis de plantas localizadas entre as coordenadas $15^{\circ} 52,35^{\prime}$ a $16^{\circ} 00,15^{\prime}$ de latitude sul e $48^{\circ} 56,72^{\prime}$ a $49^{\circ} 04,25^{\prime}$ de longitude oeste e altitude variando de 758 a 865 metros. Na região Sudeste, os frutos foram coletados no município de Orizona de plantas situadas entre as coordenadas $16^{\circ} 44,21^{\prime}$ a $16^{\circ} 47,96^{\prime}$ de latitude sul e $48^{\circ} 10,89^{\prime}$ a $48^{\circ} 14,09^{\prime}$ de longitude oeste e altitude variando de 783 a 960 metros.

\subsection{PREPARO DAS AMOSTRAS}

Após a coleta, os frutos foram transportados em sacos de polipropileno trançado até o laboratório de Frutas e Hortaliças da Escola de Agronomia e Engenharia de Alimentos da Universidade Federal de 
Goiás (UFG), sendo higienizados, processados e armazenados. Todas as etapas do processamento do baru estão mostradas na Figura 1.

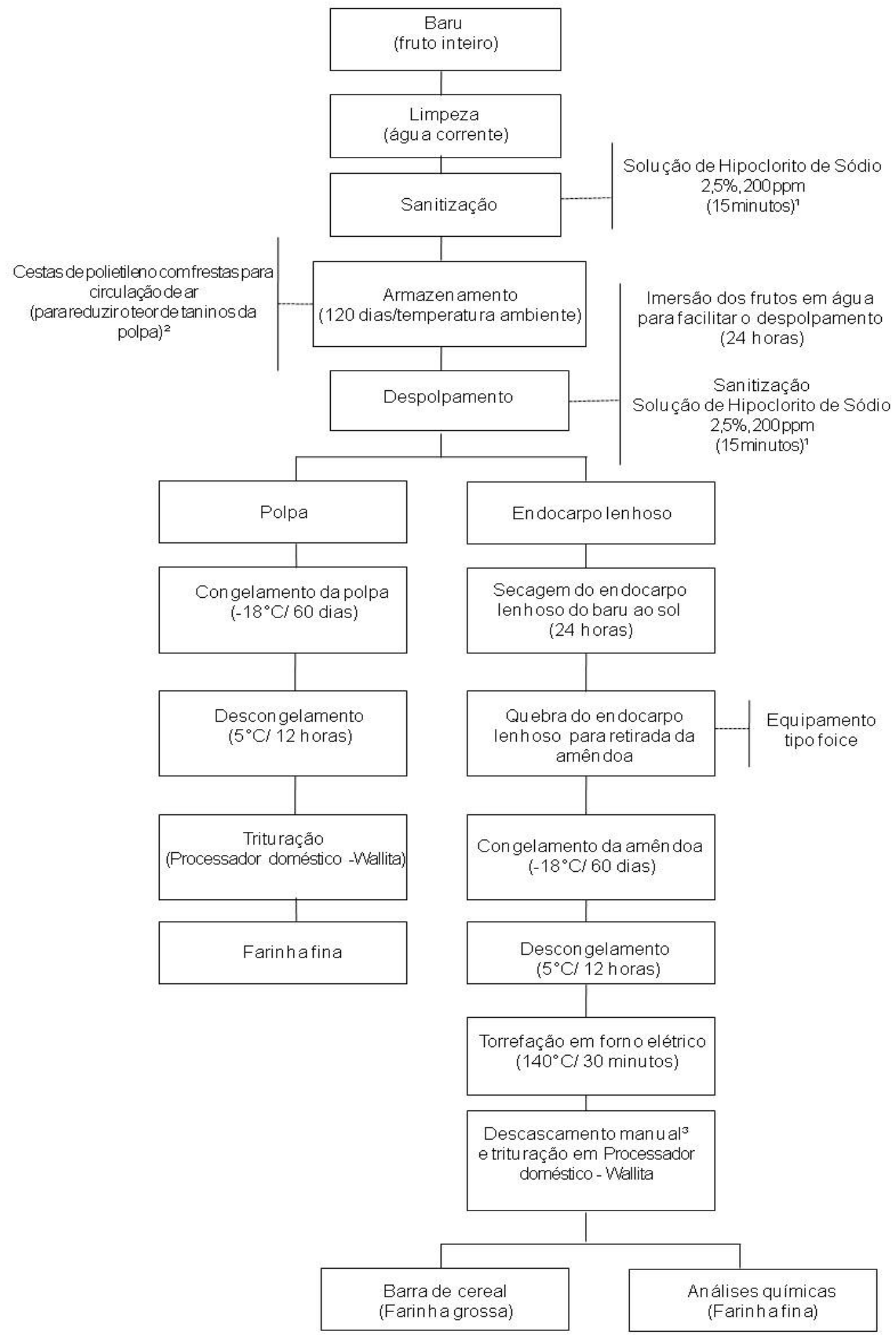

FIGURA 1 - FLUXOGRAMA DO PROCESSAMENTO DA POLPA E AMÊNDOA DE BARU

1,2 Segundo SILVA (2000) e ALVES et al. (2010), respectivamente.

${ }^{3}$ Retirada do tegumento que envolve a amêndoa de baru. 
Os ingredientes usados na formulação das barras (mel, açúcar mascavo, lecitina de soja, flocos de arroz, farelo de aveia e flocos de aveia) foram adquiridos no comércio da cidade de Goiânia (GO).

\subsection{ELABORAÇÃO DAS BARRAS DE CEREAIS}

Foram realizados testes preliminares para a padronização da formulação básica das barras de cereais, segundo GUIMARÃES e SILVA (2009), com as seguintes adaptações: substituição de glicose de milho por mel e açúcar mascavo a fim de agregar valor nutricional e preservar os hábitos alimentares regionais. As frutas secas foram substituídas por amêndoas de baru e o farelo de aveia foi substituído parcialmente pela polpa de baru, com o objetivo de aproveitar integralmente esse fruto do Cerrado. Desse modo, para a elaboração das barras de cereais foram utilizados os seguintes ingredientes, conforme ordem de adição: mel, açúcar mascavo, água, lecitina de soja, flocos de arroz, farelo de aveia, flocos de aveia, polpa e amêndoa de baru.

Para avaliar a contribuição da polpa e da amêndoa de baru na aceitabilidade e no valor nutricional das barras de cereais foram preparadas formulações com proporção fixa de amêndoa em substituição às nozes (castanha-de-caju, castanha-do-pará e amêndoas) e às frutas secas (banana-passa, uva-passa), comumente utilizadas em barras de cereais, e proporções crescentes de polpa de baru em substituição ao farelo de aveia. Após testes preliminares, foram estabelecidas três formulações a partir da formulação base, contendo 0\%, 5\% e 10\% de polpa de baru (Tabela 1). O percentual máximo de adição de polpa de baru nas formulações foi de $10 \%$, pois acima dessa quantidade a obtenção das barras de cereais tornouse tecnologicamente inviável por causa da textura e umidade da polpa de baru.

\section{TABELA 1- FORMULAÇÕES DE BARRA DE CEREAIS CONTENDO POLPA E AMÊNDOA DE} BARU

\begin{tabular}{lrcc}
\hline \multirow{2}{*}{ Ingredientes (\%) } & \multicolumn{3}{c}{ Formulações $^{1}$} \\
\cline { 2 - 4 } & BC & B5\% & B10\% \\
\hline Mel & 30 & 30 & 30 \\
Açúcar mascavo & 5 & 5 & 5 \\
Água & 3 & 3 & 3 \\
Lecitina de soja & 3 & 3 & 3 \\
Flocos de arroz & 15 & 15 & 15 \\
Farelo de aveia & 15 & 10 & 5 \\
Flocos de aveia & 15 & 15 & 15 \\
Polpa de baru & 0 & 5 & 10 \\
Amêndoa de baru torrada & 14 & 14 & 14 \\
\hline
\end{tabular}

${ }^{1} \mathrm{BC}=$ Barra de cereais controle; B5\% = Barra de cereais com 5\% de polpa de baru; B10\% = Barra de cereais com $10 \%$ de polpa de baru.

Para a elaboração das barras de cereais, todos os ingredientes foram pesados separadamente. Em seguida, os ingredientes líquidos e o açúcar mascavo foram misturados e aquecidos. Posteriormente, os flocos de arroz, farelo e flocos de aveia e as amêndoas de baru foram homogeneizados e acrescentados à mistura. A polpa de baru foi adicionada aos ingredientes sólidos.

A mistura foi submetida à cocção em calor seco $\left(90^{\circ} \mathrm{C}\right)$ por, aproximadamente, 5 minutos até a obtenção de massa homogênea. A massa foi acondicionada em formas de alumínio $(15 \mathrm{~cm} \times 6 \mathrm{~cm})$, previamente untadas com lecitina de soja. A massa ainda quente foi prensada contra o fundo de forma de alumínio de mesmo tamanho até espessura aproximada de $1 \mathrm{~cm}$, com posterior corte com aproximadamente $3 \mathrm{~cm}$ de largura e $10 \mathrm{~cm}$ de comprimento. 


\subsection{ANÁLISE MICROBIOLÓGICA}

Foram realizadas análises microbiológicas da polpa e da amêndoa de baru (contagem de coliformes a $45^{\circ} \mathrm{C}$, pesquisa de Salmonella sp em $25 \mathrm{~g}$, contagem de Bacillus cereus e contagem de Estafilococos coagulase positiva), consideradas como polpa de fruta e castanha, respectivamente, e das barras de cereais (contagem de coliformes a $45^{\circ} \mathrm{C}$, pesquisa de Salmonella sp em $25 \mathrm{~g}$, contagem de Bacillus cereus e contagem de Estafilococos coagulase positiva), segundo a RDC no 12 que regulamenta os Padrões Microbiológicos para Alimentos (BRASIL, 2001). As análises microbiológicas seguiram os procedimentos descritos pela American Public Health Association (APHA, 2001).

\subsection{TESTES DE ACEITAÇÃO}

Os testes de aceitação global (sabor, aroma e textura) e aparência das barras de cereais foram conduzidos com a participação de quarenta e quatro consumidores potenciais do produto, não treinados, conforme o interesse e disponibilidade em participar das análises. Os voluntários assinaram o termo de consentimento livre e esclarecido, aprovado pelo Comitê de Ética em Pesquisa da UFG (Protocolo COEP $n^{\circ}$ 153/2008). Os julgadores avaliaram as amostras, mediante escala estruturada de nove pontos, variando de 1 (desgostei muitíssimo) a 9 (gostei muitíssimo) (STONE e SIDEL, 1985). O intervalo dos escores 6 a 9 foi considerado como região de aceitação e o intervalo dos escores 1 a 4 como região de rejeição do produto. O escore 5 , ponto intermediário, foi considerado como ponto de indecisão.

Para avaliação dos atributos da aceitação global, $10 \mathrm{~g}$ de barras de cereais elaboradas com a polpa e a amêndoa de baru foram dispostas em pratos descartáveis, codificados com algarismos de três dígitos aleatórios e diferentes para cada julgador, em cabines individuais iluminadas com luz vermelha. A aparência das amostras foi avaliada de forma independente da análise de aceitação global, em ambiente iluminado com luz fluorescente. Avaliou-se, também, a intenção de compra das barras de cereais por meio de escala estruturada de cinco pontos ( 1 = certamente não compraria; 2 = provavelmente não compraria, $3=$ talvez compraria, 4 = provavelmente compraria e $5=$ certamente compraria).

\subsection{ANÁLISE DA COMPOSIÇÃO CENTESIMAL}

A composição centesimal das barras de cereais, da polpa e da amêndoa de baru foram determinadas em três replicatas, por meio de análises de umidade (INSTITUTO ADOLFO LUTZ, 2005); nitrogênio total, segundo o método de micro-Kjeldahl e conversão em proteína bruta utilizando-se o fator 6,25 (AOAC, 1990); lipídios totais, extraídos por meio da técnica de BLIGH e DYER (1959) e posteriormente determinados por gravimetria; resíduo mineral fixo por incineração em mufla a $550^{\circ} \mathrm{Ce}$ fibra alimentar total, solúvel e insolúvel pelo método gravimétrico-enzimático (AOAC, 1990). Os carboidratos totais foram estimados por diferença, subtraindo-se de cem os valores obtidos para umidade, proteínas, lipídios, resíduo mineral fixo e fibra alimentar (solúvel e insolúvel). A partir dos dados da composição centesimal, o valor energético das amostras foi estimado considerando-se os fatores de conversão de Atwater de 4, 4 e $9 \mathrm{kcal} / \mathrm{g}$ para proteína, carboidrato e lipídio, respectivamente (MERRIL e WATT, 1973).

\subsection{ANÁLISE ESTATÍSTICA}

Os resultados das análises de aceitabilidade e da composição centesimal das barras de cereais foram submetidos à análise de variância (ANOVA) e teste de média de Tukey, a 5\% de probabilidade de erro. Além disso, utilizou-se histograma de frequências para descrição dos resultados obtidos no teste de aceitação global e aparência das barras de cereais. Os cálculos estatísticos foram efetuados com auxílio do programa Statistica (STATSOFT, 2004). 


\section{RESULTADOS E DISCUSSÃO}

\subsection{QUALIDADE MICROBIOLÓGICA}

Na Tabela 2 estão apresentados os resultados da análise microbiológica do baru e das formulações de barras de cereais. Os dados indicam que todas as amostras estão de acordo com os padrões microbiológicos estabelecidos pela RDC n¹2, da Agência Nacional de Vigilância Sanitária do Ministério da Saúde (BRASIL, 2001), confirmando que os procedimentos de higienização realizados para a elaboração das barras de cereais, assim como sua manipulação adequada garantiram a segurança microbiológica do produto.

\section{TABELA 2 - CONTAGEM DE MICRO-ORGANISMOS EM POLPA E AMÊNDOA DE BARU E EM BARRAS DE CEREAIS COM POLPA E AMÊNDOA DE BARU}

\begin{tabular}{|c|c|c|c|c|c|}
\hline \multirow{2}{*}{ Análise microbiológica (UFC/g)1 } & \multicolumn{2}{|c|}{ Baru² } & \multicolumn{3}{|c|}{ Barra de cereais 3} \\
\hline & polpa & amêndoa & $\mathrm{BC}$ & $\mathrm{B} 5 \%$ & $\mathrm{~B} 10 \%$ \\
\hline Contagem de coliformes a $45 \mathrm{C}$ & $<100$ & $<100$ & $<50$ & $<50$ & $<50$ \\
\hline Contagem de Bacillus cereus & $<100$ & $<100$ & $<500$ & $<500$ & $<500$ \\
\hline $\begin{array}{l}\text { Contagem de Estafilococos } \\
\text { coagulase positiva }\end{array}$ & $<100$ & $<100$ & $<100$ & $<100$ & $<100$ \\
\hline $\begin{array}{l}\text { Pesquisa de Salmonella sp.em } \\
25 \mathrm{~g}\end{array}$ & ausente & ausente & ausente & ausente & ausente \\
\hline
\end{tabular}

\footnotetext{
1 Unidade formadora de colônia/g.

2 Padrões microbiológicos para castanhas (BRASIL, 2001): contagem de coliformes a $45^{\circ} \mathrm{C}$ : $10^{3} \mathrm{UFC} / \mathrm{g}$; contagem de Bacillus cereus: < $10^{2} \mathrm{UFC/g}$; contagem de Estafilococos coagulase positiva: < $10^{2} \mathrm{UFC/g}$; pesquisa de Salmonella $s p$ em $25 \mathrm{~g}$ : ausência em $25 \mathrm{~g}$. Padrões microbiológicos para polpa de fruta (BRASIL, 2001): contagem de coliformes a $45^{\circ} \mathrm{C}$ : $5 \times 10^{2} \mathrm{UFC} / \mathrm{g}$; contagem de Bacillus cereus: < $10^{2} \mathrm{UFC} / \mathrm{g}$; contagem de Estafilococos coagulase positiva: $<10^{2} \mathrm{UFC} / \mathrm{g}$; pesquisa de Salmonella sp em $25 \mathrm{~g}$ : ausência em $25 \mathrm{~g}$.

${ }^{3}$ (BC) Barra de cereais controle; (B5\%) Barra de cereais com 5\% de polpa de baru; (B10\%) Barra de cereais com 10\% de polpa de baru. Padrões microbiológicos para barra de cereal (BRASIL, 2001): contagem de coliformes a $45^{\circ} \mathrm{C}: 5 \times 10^{2}$ UFC/g; contagem de Bacillus cereus: 5 × $10^{3} \mathrm{UFC/g}$; contagem de Estafilococos coagulase positiva: 1030FC/g; pesquisa de Salmonella $s p$ em $25 \mathrm{~g}$ : ausência em $25 \mathrm{~g}$.
}

\subsection{ACEITABILIDADE}

Os resultados de aceitação das barras de cereais estão apresentados na Tabela 3. Observase que as formulações de barras de cereais, independente das porcentagens de polpa de baru adicionadas, apresentaram boa aceitação global (sabor, aroma e textura), com valores médios acima de 7 e superiores aos observados em estudo com barras de cereais de murici-passa e banana-passa, que obtiveram o valor médio de 6,27 (GUIMARÃES e SILVA, 2009).

Ressalta-se que no mínimo $50 \%$ dos julgadores atribuíram escores igual ou superior a 8 para a aceitação global das três formulações de barras de cereais, conforme pode ser visualizado na Figura 2.

Quanto à aparência, as médias dos escores atribuídos para todas as barras de cereais foram superiores a 7, sem diferença significativa entre elas. A boa aceitação das barras de cereais 
também pode ser confirmada por meio do histograma de distribuição de frequências (Figura 3), no qual se observa que no mínimo $43 \%$ dos julgadores atribuíram escores 8 ou 9 para as três formulações.

\section{TABELA 3 - ESCORES DE ACEITAÇÃO DAS BARRAS DE CEREAIS COM RELAÇÃO À ACEITAÇÃO GLOBAL (SABOR, AROMA E TEXTURA), APARÊNCIA E INTENÇÃO DE COMPRA ${ }^{1}$}

\begin{tabular}{lccc}
\hline $\begin{array}{l}\text { Barra de } \\
\text { cereais }^{2}\end{array}$ & $\begin{array}{c}\text { Aceitação } \\
\text { global }^{3}\end{array}$ & Aparência $^{3}$ & Intenção de compra $^{4}$ \\
\hline BC & $7,61 \pm 1,24^{\mathrm{a}}$ & $7,61 \pm 1,24^{\mathrm{a}}$ & $3,86 \pm 1,05^{\mathrm{a}}$ \\
B5\% & $7,34 \pm 1,27^{\mathrm{a}}$ & $7,45 \pm 1,28^{\mathrm{a}}$ & $3,89 \pm 0,78^{\mathrm{a}}$ \\
B10\% & $7,14 \pm 1,79^{\mathrm{a}}$ & $7,07 \pm 1,47^{\mathrm{a}}$ & $3,70 \pm 1,21^{\mathrm{a}}$ \\
\hline
\end{tabular}

1 Valores médios \pm desvio-padrão. Médias com letras iguais, na mesma coluna, não diferem estatisticamente entre si (Teste de Tukey a $5 \%$ de probabilidade).

2 (BC) Barra de cereais controle; (B5\%) Barra de cereais com 5\% de polpa de baru; (B10\%) Barra de cereais com 10\% de polpa de baru.

${ }^{3}$ Escores para aceitação global e aparência - 1: desgostei muitíssimo; 6: gostei levemente; 9: gostei muitíssimo.

${ }^{4}$ Escores para intenção de compra - 1:certamente eu não compraria; 3: talvez eu compraria; 5: certamente eu compraria.

De acordo com o teste de intenção de compra, todas as barras de cereais provavelmente seriam adquiridas pelos julgadores, uma vez que apresentaram escore aproximado de 4 (Tabela 3). GUTKOSKI et al. (2007), em estudo com barra de cereais à base de aveia com alto teor de fibra alimentar obtiveram intenção de compra com valor médio de 3,95.

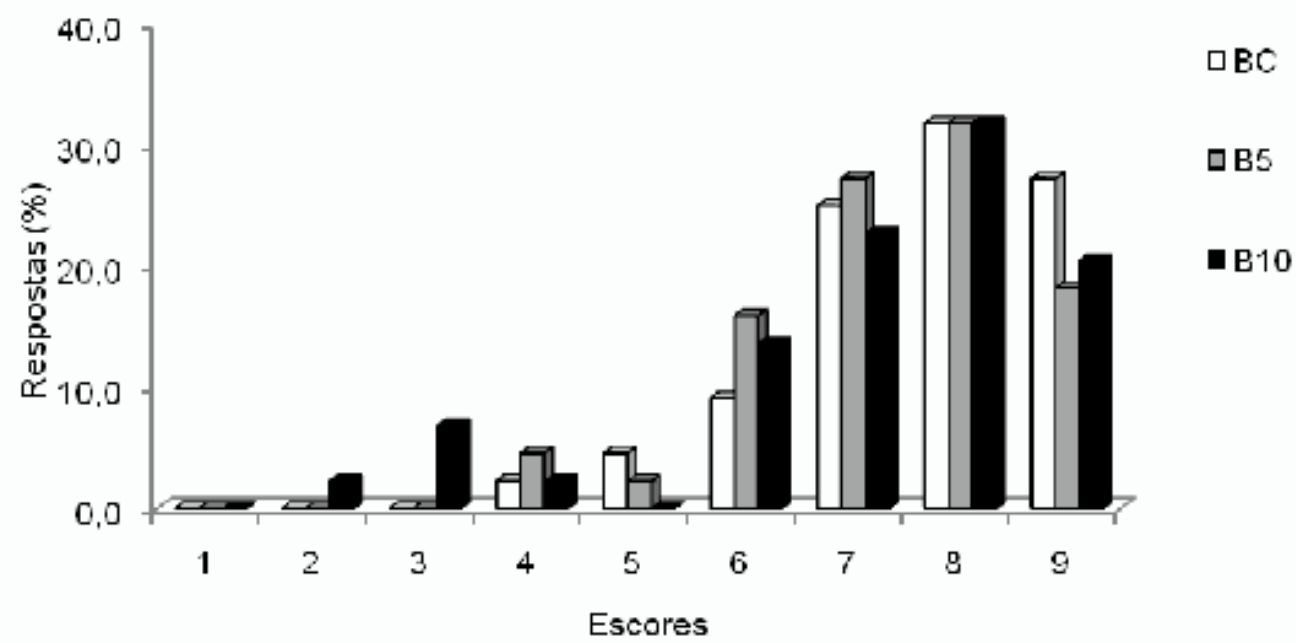

FIGURA 2 - HISTOGRAMA DE FREQUÊNCIA DOS ESCORES DE ACEITAÇÃO GLOBAL (SABOR, AROMA E TEXTURA) DAS BARRAS DE CEREAIS

(BC) Barra de cereais controle; (B5\%) Barra de cereais com 5\% de polpa de baru; (B10\%) Barra de cereais com 10\% de polpa de baru.

(Escores de aceitação global: 1-desgostei muitíssimo; 6-gostei levemente; 9-gostei muitíssimo). 


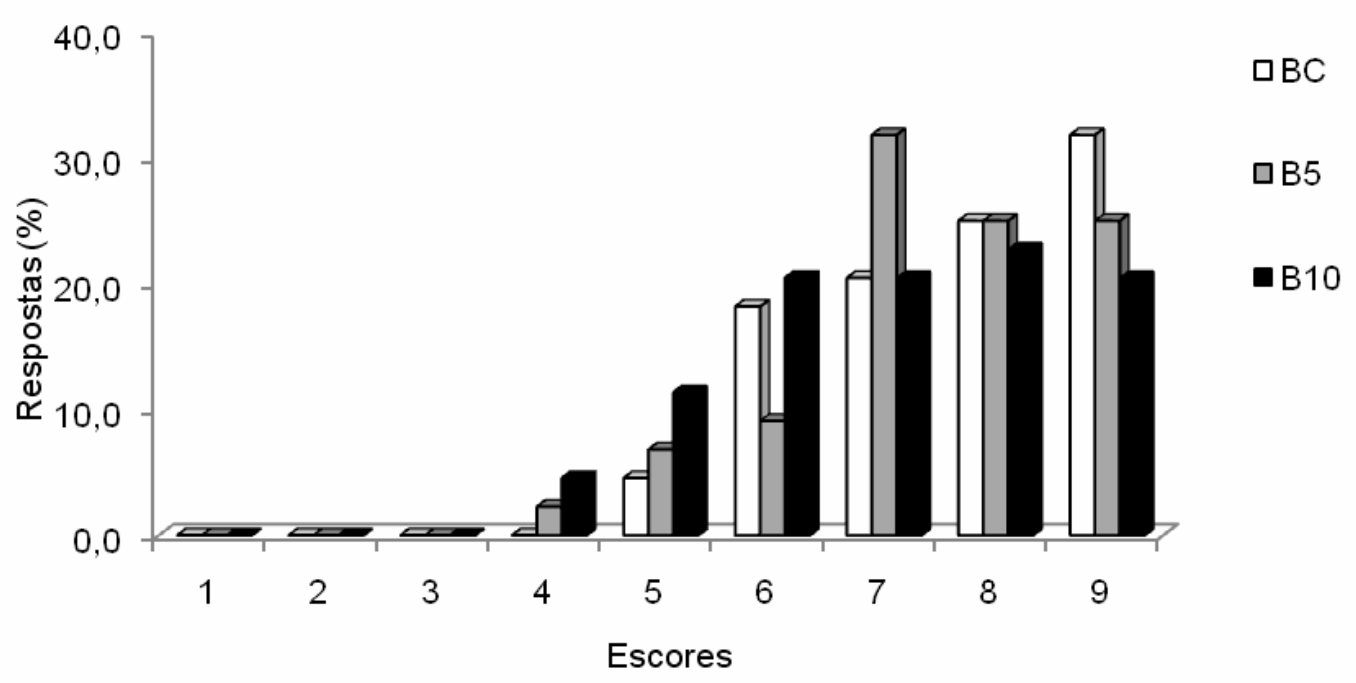

\section{FIGURA 3 - HISTOGRAMA DE FREQUÊNCIA DOS ESCORES DE APARÊNCIA DAS BARRAS DE CEREAIS}

(BC) Barra de cereais controle; (B5\%) Barra de cereais com 5\% de polpa de baru; (B10\%) Barra de cereais com 10\% de polpa de baru.

(Escores de aparência: 1-desgostei muitíssimo; 6-gostei levemente; 9-gostei muitíssimo).

\subsection{COMPOSIÇÃO CENTESIMAL}

\subsubsection{Amêndoa de baru}

A amêndoa de baru torrada apresentou baixo teor de umidade (Tabela 4), fato já observado por FERNANDES et al. (2010) que obtiveram entre 3,20 g/100 g e 4,00 g/100 g de umidade para amêndoas de baru oriundas da região Sudeste do estado de Goiás. Esse valor pode ser explicado pela própria característica de baixa umidade do alimento in natura, entre 5,80 g/100 g a 6,10 g/100 g (TAKEMOTO et al., 2001; VALLILO, TAVARES e AUED, 1990), que foi reduzida pelas condições de torrefação das amêndoas neste estudo.

Quanto ao teor de cinzas das amêndoas (Tabela 4), os valores estão próximos aos relatados na literatura, entre 2,63 g/100 g e 2,85 g/100 g (TAKEMOTO et al., 2001; TOGASHI e SGARBIERI, 1994; TOGASHI e SGARBIERI, 1995; VALLILO, TAVARES e AUED, 1990).

A amêndoa de baru apresentou alto teor de lipídios (Tabela 4), similar ao constatado por VALLILO, TAVARES e AUED (1990) que relataram 41,65 g/100 g, e próximo ao de amêndoas de baru da região Sudeste do estado de Goiás, de 41,97 g/100 g (FERNANDES et al., 2010).

A quantidade de proteína da amêndoa (Tabela 4) superou valores encontrados em outros estudos, que variaram entre $22 \mathrm{~g} / 100 \mathrm{~g} \mathrm{e} 25 \mathrm{~g} / 100 \mathrm{~g}$. Essa diferença pode ser explicada porque nesses trabalhos a amêndoa de baru foi caracterizada in natura (TAKEMOTO et al., 2001; TOGASHI e SGARBIERI, 1994; TOGASHI e SGARBIERI, 1995; VALLILO, TAVARES e AUED, 1990).

Quanto ao teor de fibra, a amêndoa apresentou quantidade de fibra total um pouco acima do relatado por TAKEMOTO et al. (2001). A fração insolúvel está acima da constatada no referido estudo, que foi de aproximadamente $10 \mathrm{~g} / 100 \mathrm{~g}$. 


\section{TABELA 4 - COMPOSIÇÃO CENTESIMAL E VALOR ENERGÉTICO DO BARU E DAS BARRAS DE CEREAIS ${ }^{1}$}

\begin{tabular}{lcccccc}
\hline Componente $^{2}$ & \multicolumn{2}{c}{ Baru } & & \multicolumn{3}{c}{ Barra de cereais $^{3}$} \\
\cline { 2 - 3 } \cline { 5 - 7 } (g/100 g) & amêndoa & polpa & & BC & B5\% & B10\% \\
\hline Umidade & $3,23 \pm 0,08$ & $24,45 \pm 0,18$ & & $9,73 \pm 0,35^{\mathrm{c}}$ & $10,30 \pm 0,08^{\mathrm{b}}$ & $12,82 \pm 0,06^{\mathrm{a}}$ \\
Cinzas & $3,03 \pm 0,04$ & $2,00 \pm 0,06$ & & $1,37 \pm 0,03^{\mathrm{a}}$ & $1,33 \pm 0,02^{\mathrm{a}}$ & $1,44 \pm 0,11^{\mathrm{a}}$ \\
Proteína & $26,97 \pm 0,63$ & $5,88 \pm 0,10$ & & $11,23 \pm 0,23^{\mathrm{a}}$ & $10,45 \pm 0,73^{\mathrm{a}}$ & $10,23 \pm 0,19^{\mathrm{a}}$ \\
Lipídios & $40,98 \pm 0,74$ & $3,57 \pm 0,10$ & & $11,06 \pm 0,63^{\mathrm{a}}$ & $10,48 \pm 0,22^{\mathrm{a}}$ & $10,77 \pm 0,26^{\mathrm{a}}$ \\
Carboidratos & 11,53 & 22,50 & & 51,05 & 50,71 & 49,88 \\
FAT & $14,26 \pm 0,13$ & $41,60 \pm 0,10$ & & $15,56 \pm 0,20^{\mathrm{a}, \mathrm{b}}$ & $16,73 \pm 0,90^{\mathrm{a}}$ & $14,86 \pm 0,50^{\mathrm{b}}$ \\
FI & $13,35 \pm 0,17$ & $39,50 \pm 0,20$ & & $9,13 \pm 0,40^{\mathrm{c}}$ & $10,40 \pm 0,40^{\mathrm{b}}$ & $12,70 \pm 0,25^{\mathrm{a}}$ \\
FS & $0,90 \pm 0,05$ & $2,10 \pm 0,17$ & & $6,43 \pm 0,51^{\mathrm{a}}$ & $6,33 \pm 0,42^{\mathrm{a}}$ & $2,13 \pm 0,23^{\mathrm{b}}$ \\
VET (kcal) & 522,82 & 145,65 & & $348,66^{\mathrm{a}}$ & $338,96^{\mathrm{b}}$ & 2,13 \\
\hline
\end{tabular}

${ }^{1}$ Valores constituem médias \pm desvios-padrão de 3 repetições, com exceção dos carboidratos totais que foram estimados por diferença, e do VET (valor energético total) que foi estimado conforme fatores de conversão para cada macronutriente. Médias com letras iguais, na mesma linha, não diferem estatisticamente entre si (Teste de Tukey a 5\% de probabilidade). 2 (FAT) Fibra alimentar total, (FI) Fibra insolúvel, (FS) Fibra solúvel.

${ }^{3}$ (BC) Barra de cereais controle; (B5\%) Barra de cereais com 5\% de polpa de baru; (B10\%) Barra de cereais com 10\% de polpa de baru.

\subsubsection{Polpa de baru}

A polpa de baru apresentou teor de umidade (Tabela 4) ligeiramente maior que o relatado na literatura, de aproximadamente $20 \mathrm{~g} / 100 \mathrm{~g}$ (VALLILO, TAVARES e AUED, 1990) em razão dos frutos terem sido imersos em água para facilitar o despolpamento (Figura 1). O conteúdo de cinzas encontrado para a polpa de baru foi de $2 \mathrm{~g} / 100 \mathrm{~g}$, assemelhando-se ao relatado por VALLILO, TAVARES e AUED (1990). A polpa de baru pode representar fonte de minerais para a população regional pelo seu conteúdo de cinzas, superior ao de outras polpas de frutos do Cerrado (SILVA et al., 2008).

O baixo conteúdo de lipídios e de proteína encontrados na polpa de baru (Tabela 4) ficou próximo dos valores observados na literatura (TOGASHI e SGARBIERI, 1994; VALLILO, TAVARES e AUED, 1990). Em relação ao teor de carboidratos da polpa de baru (Tabela 4), os valores encontrados estão abaixo de 28,71 g/100 g relatado na literatura (TOGASHI e SGARBIERI, 1994).

Quanto ao teor de fibras alimentares (Tabela 4), a polpa de baru apresentou valores superiores aos encontrados por TOGASHI e SGARBIERI (1994) para o conteúdo total e para as frações insolúvel e solúvel, de 29,5 g/100 g, 28,2 g/100 g e 1,3 g/100 g, respectivamente. A maior concentração de fibras observada neste estudo pode estar associada ao tempo decorrido entre a coleta e o processamento completo da polpa (Figura 1). Esse fato também foi observado em estudo prévio de ALVES et al. (2010), que detectaram aumento expressivo no conteúdo de fibra alimentar da polpa de baru após 136 dias de coleta. Provavelmente, parte do amido da polpa de baru foi convertido a amido resistente, $\mathrm{e}$ esse foi detectado nas análises como fibra insolúvel (LOBO e SILVA, 2003; ALVES et al., 2010).

\subsubsection{Barras de cereais}

As barras de cereais diferiram entre si quanto aos valores de umidade, variando de $9 \mathrm{~g} / 100 \mathrm{~g}$ a $13 \mathrm{~g} / 100 \mathrm{~g}$. Ressalta-se que os teores de umidade de todas as barras de cereais ficaram abaixo de $15 \%$, limite estabelecido pela Resolução CNNPA n 12 de 1978 para produtos à base de cereais (BRASIL, 1978), o que contribui para armazenamento estável e sem alterações importantes na qualidade do produto (ESTÉVEZ, ESCOBAR e UGARTE, 2000). O teor reduzido de umidade contribui para a preservação da qualidade tecnológica das barras de cereais por favorer a manutenção da crocância, atributo sensorial característico das barras de cereais (GUIMARÃES e SILVA, 2009). Além disso, os baixos teores de umidade podem evitar o escurecimento não enzimático, assim como proteger as 
barras de cereais do crescimento microbiano e, por conseguinte, aumentar a vida-de-prateleira do produto CECCHI (2003).

As barras de cereais apresentaram teores de cinzas (Tabela 4) semelhantes aos relatados por GUIMARÃES e SILVA (2009), variando entre 1,15 g/100 g e 1,38 g/100 g, e abaixo de 2,2 g/100 g, constatado por FREITAS e MORETTI (2006) em estudo com barras de cereais com alto teor protéico e vitamínico. De acordo com CECCHI (2003), os cereais apresentam conteúdo de cinzas totais entre $0,3 \mathrm{~g} / 100 \mathrm{~g} \mathrm{e}$ 3,3 g/100 g, portanto, as barras de cereais do presente estudo apresentaram conteúdo de cinzas adequado para esse tipo de produto. Considerando que o conteúdo de cinzas está relacionado ao teor de minerais do alimento, as barras contribuem para o aporte de minerais na alimentação.

O teor de lipídios constatado nas três barras de cereais mostrou-se similar ao de barras de cereais comerciais, que contêm, em média, $11 \mathrm{~g} / 100 \mathrm{~g}$ desse nutriente. Por outro lado, barras de cereais elaboradas experimentalmente apresentaram entre 5,2 g/100 g e 5,6 g/100 g de lipídios (FREITAS e MORETTI, 2006; GUIMARÃES e SILVA, 2009). O conteúdo de lipídios relativamente alto das barras de cereais do presente estudo pode ser explicado pela adição de amêndoas de baru, cujo teor de lipídios é elevado (Tabela 4). Todavia, a amêndoa de baru é rica em ácidos graxos mono e poliinsaturados, com destaque para os ácidos graxos oleico e linoleico (FREITAS e NAVES, 2010). Além disso, a amêndoa de baru apresenta relação de ácidos graxos ( $\omega-6: \omega-3$ de 9:1), benéfica para a saúde. Dietas em que a relação $\omega$-6: $\omega$-3 é de até 10:1 contribuem para a redução do risco de desenvolvimento de doenças cardiovasculares (FREITAS e NAVES, 2010; OMS, 2003). Assim, a amêndoa de baru agrega lipídios de boa qualidade às barras de cereais em comparação às formulações comerciais.

As concentrações de proteína das barras (Tabela 4) foram superiores às constatadas em barras de cereais comerciais (em torno de $6,5 \mathrm{~g} / 100 \mathrm{~g}$ ) e barras de cereais com banana-passa e murici-passa padronizadas por GUIMARÃES e SILVA (2009), que variaram entre 6,9 g/100 g e $7,7 \mathrm{~g} / 100 \mathrm{~g}$. Entretanto, são semelhantes aos valores relatados por GUTKOSKI et al. (2007) de $9,79 \mathrm{~g} / 100 \mathrm{~g}$ a $12,37 \mathrm{~g} / 100 \mathrm{~g}$, em barras de cereais à base de aveia. As barras de cereais formuladas neste estudo contêm teores relativamente elevados de proteínas por causa da adição de amêndoa de baru. Ressalta-se que, além da quantidade, a amêndoa de baru contribui para melhorar a qualidade proteica de barras de cereais, visto que sua proteína apresenta boa digestibilidade (80\%) e bom perfil de aminoácidos, satisfazendo $92 \%$ das necessidades de aminoácidos essenciais para escolares (FERNANDES et al., 2010).

As barras de cereais apresentaram conteúdo elevado de carboidratos (Tabela 4), semelhante ao de barras de cereais comerciais em decorrência da alta concentração de cereais e da adição de mel e de açúcar mascavo, sendo esse o nutriente que mais contribuiu para o valor energético do produto.

As barras de cereais formuladas com polpa e amêndoa de baru destacam-se, ainda, em relação às altas concentrações de fibras alimentares (aproximadamente $15 \mathrm{~g} / 100 \mathrm{~g}$ ), superiores às de barras de cereais comerciais e de barras formuladas com adição de banana-passa e murici-passa (GUIMARÃES e SILVA, 2009) que apresentam, em média, $6 \mathrm{~g} / 100 \mathrm{~g}$. Assim, as barras de cereais elaboradas no presente estudo constituem alimentos com alto teor de fibras (BRASIL, 1998). A substituição parcial de farelo de aveia por polpa de baru elevou o teor de fibra insolúvel do produto, o que é favorável à saúde. O consumo de fibras insolúveis está associado ao aumento do bolo fecal e à prevenção de problemas entéricos, que acometem grande parte da população, sobretudo as mulheres (BRAND-MILLER, 2002).

Quanto ao valor energético estimado, as barras de cereais evidenciaram valores entre $337 \mathrm{kcal} / 100 \mathrm{~g}$ e $349 \mathrm{kcal} / 100 \mathrm{~g}$. As barras de cereais com polpa de baru apresentaram menor valor calórico em relação à formulação sem polpa. Assim, o uso da polpa de baru reduziu o valor energético das barras (Tabela 4). Em trabalho anterior foi constatado que a adição de prebióticos como inulina, oligofrutose e goma de acácia às barras de cereais reduziu seu valor energético (DUTCOSKY et al., 2006). A redução do valor energético de barras de cereais constitui vantagem para a indústria de alimentos, uma vez que a procura por esse tipo de alimento está cada vez mais associada à dieta equilibrada e saudável. 
Barras de cereais formuladas com polpa e amêndoa de baru podem ser consideradas alimentos saudáveis em razão de seus altos teores de proteínas e fibras. Nesse sentido, WILLIAMS et al. (2006) encontraram evidências de que barras tipo snack com maior conteúdo de proteínas e fibras melhoram os parâmetros metabólicos e podem auxiliar no controle do apetite, quando comparadas a barras convencionais com alto teor de lipídeos e carboidratos refinados.

\section{CONCLUSÃo}

As barras de cereais formuladas com $14 \%$ de amêndoa de baru e $0 \%, 5 \%$ e $10 \%$ de polpa de baru foram bem aceitas por consumidores potenciais de barras de cereais.

A adição de polpa de baru na elaboração de barras de cereais, em substituição ao farelo de aveia, não influenciou a aceitabilidade do produto e melhorou seu valor nutricional, aumentando o teor de fibras insolúveis e reduzindo o valor energético.

Barras de cereais formuladas com a polpa e amêndoa de baru são fontes de energia, proteínas e carboidratos, e também apresentam alto teor de fibra alimentar.

A utilização integral do baru em alimentos processados é recomendável para agregar valor ao fruto e qualidade nutricional ao produto, contribuindo para o uso sustentável desse fruto nativo.

\section{ABSTRACT \\ MICROBIOLOGICAL QUALITY, ACCEPTABILITY AND NUTRITIONAL VALUE OF CEREAL BARS FORMULATED WITH BARU PULP AND ALMOND}

The aim of this study was to evaluate the microbiological quality, the acceptability and the nutritional characteristics of cereal bars made with pulp and almond of the baru (native fruit from Brazilian Savanna). The fruits were collected in the East and South East Regions from Goiás state, in August 2008. The formulations of cereal bars were prepared with fixed proportion of almond in replacement to the nuts and dried fruits, and increasing proportions of baru pulp (0\%,5\% and 10\%) in replacement to the oat bran. The cereal bars were evaluate for microbiological quality through counts of coliforms, Bacillus cereus, positive Staphylococci coagulase and Salmonella, and for the overall acceptance, appearance and purchase intent. The accepted bars were submitted to the analysis of centesimal composition, including total dietary fiber and its fractions (soluble and insoluble). All the samples were in accordance with the microbiological standard for food. The cereal bars had good overall acceptance and good levels of purchase intent, and showed levels of carbohydrates and lipids similar to the commercial cereal bars and high protein content $(10.64 \mathrm{~g} / 100 \mathrm{~g})$, due to the addition of baru almond, a source of protein and lipids of good nutritional quality. Cereal bars made with the pulp and almond of the baru are source of energy, proteins and carbohydrates and present a high level of dietary fiber $(15.72 \mathrm{~g} / 100 \mathrm{~g})$. The full utilization of baru in processed foods adds value to the fruit and nutritional quality to the product, contributing to the sustainable use of this native fruit.

KEY-WORDS: Dipteryx alata Vog.; CEREAL BARS; NUTRITIONAL VALUE; ACCEPTABILITY.

\section{REFERÊNCIAS}

1 ALVES, A. M.; MENDONÇA, A. L.; CALIARI, M.; CARDOSO-SANTIAGO, R. A. Avaliação química e física de componentes do baru (Dipteryx alata Vog.) para estudo da vida-de-prateleira. Pesquisa Agropecuária Tropical, Goiânia, v. 40, n. 3, p. 266-273, 2010.

2 AOAC. Association of Official Analytical Chemists. Official methods of analysis of AOAC International. $15^{\text {th }}$ ed. Arlington, 1990.

3 APHA. American Public Health Association. Compendium of methods for the microbiological examination of foods. $4^{\text {th }}$ ed. Washington, 2001.

4 BLIGH, E. G.; DYER, W. J. A rapid method of total lipid extraction and purification. Canadian Journal of Biochemistry and Physiology, Toronto, v.37, n.8, p. 911-917, 1959. 
5 BRAND-MILLER, J. Carbohydrates. In: MANN, J.; TRUSWELL, S. Essentials of human nutrition. $2^{\text {nd }}$ ed. New York: Oxford University Press, 2002. p. 11-29.

6 BRASIL. Agência Nacional de Vigilância Sanitária. Resolução CNNPA n.12, de 1978: normas técnicas especiais. Normas técnicas especiais para alimentos e bebidas. Brasília, 1978. Disponível em: <http://www.anvisa.gov.br/legis/ resol/12_78.pdf>. Acesso em: 22 jul. 2009.

7 BRASIL. Agência Nacional de Vigilância Sanitária. Portaria nº 27, de 13 de janeiro de 1998. Aprova o regulamento técnico referente à informação nutricional complementar. Brasília, 1998. Disponível em: <http://e-legis.anvisa.gov.br/ leisref/public/showAct.php?id=97>. Acesso em: 27 out. 2009.

8 BRASIL. Agência Nacional de Vigilância Sanitária. Resolução RDC n.12, de 02 de janeiro de 2001. Aprova o regulamento técnico sobre os padrões microbiológicos para alimentos. Brasília, 2001. Disponível em: <http:// www.anvisa.gov.br/legis/resol/12_01rdc.htm>. Acesso em: 27 out. 2009.

9 CASTRO, A. M. Flavors from the Cerrado: smell, taste, absorb, love them. Brasília: Ministério das Relações Exteriores, 2009. 7 p. (Texts from Brazil, n. 13). Disponível em: <http://www.mre.gov.br/dc/english/textos/revistaing13mat13.pdf>. Acesso em: 16 nov. 2009.

10 CECCHI, H. M. Fundamentos teóricos e práticos de análise de alimentos. 2. ed. Campinas: Unicamp, 2003.

11 CORRÊA, G. C. Avaliação comportamental de plantas de baru (Dipteryx alata Vog.) nos cerrados do estado de Goiás. 1999. 110 f. Tese (Doutorado em Agronomia) - Escola de Agronomia e Engenharia de Alimentos, Universidade Federal de Goiás, Goiânia, 1999.

12 DUTCOSKY, S. D.; GROSSMAN, M. V. E.; SILVA, R. S. S. F.; WELSCH, A. K. Combined sensory optimization of a prebiotic cereal product using multicomponent mixture experiments. Food Chemistry, London, v.98, n.4, p. 630-638, 2006.

13 ESTÉVEZ, A. M.; ESCOBAR, B. A.; UGARTE, V. A. Utilización de cotilédones de algarobo [Prosopis chilensis (Moe) Stuntz] em la elboración de barra de cereales. Archivos Latinoamericanos de Nutrición, Caracas, v.50, n.2, p. 148-154, 2000.

14 FERNANDES, D. C.; FREITAS, J. B.; CZEDER, L. P.; NAVES, M. M. V. Nutritional composition and protein value of the baru (Dipteryx alata Vog.) almond from the Brazilian Savanna. Journal of the Science of Food and Agriculture, Oxford, v. 90, n. 10, p. 1650-1655, 2010.

15 FREITAS, D. G. C.; MORETTI, R. H. Caracterização e avaliação sensorial de barras de cereais funcional de alto teor protéico e vitamínico. Ciência e Tecnologia de Alimentos, Campinas, v.26, n.2, p. 318-324, 2006.

16 FREITAS, J. B.; NAVES, M. M. V. Composição química de nozes e sementes comestíveis e sua relação com a nutrição e saúde. Revista de Nutrição, Campinas, v. 23, n. 2, p. 269-279, 2010.

17 GUIMARÃES, M. M.; SILVA, M. S. Qualidade nutricional e aceitabilidade de barras de cereais adicionadas de frutos de murici-passa. Revista do Instituto Adolfo Lutz, São Paulo, v.68, n.3, p.426-433, 2009.

18 GOMES, B. Z.; MARTINS, F. R.; TAMASHIRO, J. Y. Estrutura do cerradão e da transição entre cerradão e floresta paludícola num fragmento da Internacional Paper do Brasil Ltda., em Brotas, SP. Revista Brasileira de Botânica, São Paulo, v.27, n.2, p. 249-262, 2004.

19 GUTKOSKI, L. C.; BONAMIGO, J. M. A.; TEIXEIRA, D. M. F.; PEDÓ, I. Desenvolvimento de barras de cereais à base de aveia com alto teor de fibras. Ciência e Tecnologia de Alimentos, Campinas, v.27, n.2, p. 355-363, 2007.

20 Instituto Adolfo Lutz. Normas analíticas do Instituto Adolfo Lutz: métodos físico-químicos para análise de alimentos. 4. ed. Brasília: Ministério da Saúde/Agência Nacional de Vigilância Sanitária, 2005. 1018 p.

21 LOBO, A. R.; SILVA, G. M. L. Amido resistente e suas propriedades físico-químicas. Revista de Nutrição, Campinas, v.16, n.2, p. 219-226, 2003.

22 LORENZI, H. Árvores brasileiras: manual de identificação e cultivo de plantas arbóreas nativas do Brasil. 4. ed. São Paulo: Instituto Plantarum, 2002. 368 p.

23 MARTINS, M. C. P.; CUNHA, T. L.; SILVA, M. R. Efeito das condições da desidratação osmótica na qualidade de passas de caju-do-cerrado. Ciência e Tecnologia de Alimentos, Campinas, v.28, supl., p. 158-165, 2008.

24 MERRIL, A. L.; WATT, B. K. Energy value of foods: basis and derivation. Washington: United States Departament of Agriculture, 1973. $105 \mathrm{p}$.

25 OMS. Organización Mundial de La Salud. Informe de uma consulta mixta de expertos OMS/FAO. Dieta, nutrición y prevención de enfermedades crônicas. Genebra, 2003. (OMS, Serie de Informes Técnicos, 916).

26 RABÊLO, A. M. S.; TORRES, M. C. L.; GERALDINE, R. M.; SILVEIRA, M. F. A. Extração, secagem e torrefação da amêndoa do pequi (Caryocar brasiliense Camb.). Ciência e Tecnologia de Alimentos, Campinas, v. 28, n. 4, p. 868-871, 2008. 
28 SILVA, M. R.; LACERDA, D. B. C. L.; SANTOS, G. G.; MARTINS, D. M. O. Caracterização química de frutos nativos do cerrado. Ciência Rural, Santa Maria, v.38, n.6, p. 1790-1793, 2008.

29 SILVA, J. A. Tópicos da tecnologia de alimentos. São Paulo: Livraria Varela, 2000. 227 p.

30 SOARES JÚNIOR, M. S.; CALIARI, M.; TORRES, M. C. L.; VERA, R.; TEIXEIRA, J. S.; ALVES, L. C. Qualidade de biscoitos formulados com diferentes teores de farinha de amêndoa de baru (Dipteryx alata Vog.). Pesquisa Agropecuária Tropical, Goiânia, v. 37, n.1, p. 51-56, 2007.

31 SOARES JÚNIOR, M. S.; REIS, R. C.; BASSINELO, P. Z.; LACERDA, D. B. C.; KOAKUZU, S. N.; CALIARI, M. Qualidade de biscoitos formulados com diferentes teores de farinha de casca de pequi. Pesquisa Agropecuária Tropical, Goiânia, v. 39, n.2, p. 98-104, 2009.

STATSOFT INC. Statistica. Version 7. Tulsa, 2004

STONE, H.; SIDEL, J. L. Sensory evaluation practices. Flórida: Academic Press, 1985. p. $227-252$.

34 TAKEMOTO, E.; OKADA, I. A.; GARBELOTTI, M. L.; TAVARES, M.; AUED-PIMENTEL, S. Composição química da semente e do óleo de baru (Dipteryx alata Vog.) nativo do município de Pirenópolis, estado de Goiás. Revista do Instituto Adolf Lutz, São Paulo, v.60, n.2, p. 113-117, 2001.

TOGASHI, M.; SGARBIERI, V. C. Caracterização química parcial do fruto do baru (Dipteryx alata, Vog.). Ciência e Tecnologia de Alimentos, Campinas, v.14, n.1, p.85-95, 1994.

36 TOGASHI, M.; SGARBIERI, V. C. Avaliação nutricional da proteína e do óleo de sementes de baru (Dipteryx alata Vog.). Ciência e Tecnologia de Alimentos, Campinas, v.15, n.1, p. 66-69, 1995.

37 VALLILO, M. I.; TAVARES, M.; AUED, S. Composição química da polpa e da semente do fruto do cumbaru (Dipteryx alata, Vog) - caracterização do óleo da semente. Revista do Instituto Florestal, São Paulo, v. 2, n. 2, p. 115-125, 1990.

38 VENKATACHALAM, M.; SATHE, S. K. Chemical composition of selected edible nut seeds. Journal of Agricultural and Food Chemistry, Washington, v. 54, n. 13, p. 4705-4714, 2006.

39 WILLIAMS, G.; NOAKES, M.; KEOGH, J.; FOSTER, P.; CLIFTON, P. High protein high fibre snack bars reduce food intake and improve short term glucose and insulin profiles compared with high fat snack bars. Asia Pacific Journal of Clinical Nutrition, London, v. 15, n. 4, p. 443-450, 2006. 